\title{
Long Waves and Commercialization of Technological Development in Russia in the Context of Globalization: Institutional Approach
}

\author{
Svetlana Rumyantseva ${ }^{1, *}$,Elena Korostyshevskaya ${ }^{2}$, and Gennady Alpatov $^{2}$ \\ ${ }^{1}$ St. Petersburg State University, Economic Faculty, Department of Economic Theory, 7/9 \\ Universitetskaya nab., St. Petersburg, 199034, Russia. \\ ${ }^{2}$ St. Petersburg State University, Economic Faculty, Department of Economic Theory and Economic \\ Policy, 7/9 Universitetskaya nab., St. Petersburg, 199034, Russia.
}

\begin{abstract}
.
Research background: The paper presents literature analysis and review on the considered problem.

Purpose of the article: This paper is devoted to researching the effect a phase of the long wave has on technological development commercialization (TDC) in Russia taking into account the trend which has been found for tuning a public-private partnership institution into the triple helix mechanism.

Methods: The modern phase of the long wave has been assessed empirically and statistically. The study is based on previously achieved empirical results (by some authors) in studying propensity of economic agents in Russia to introduce basic innovations and the TDC. Authors used general scientific methods of analysis and synthesis.

Findings \& Value added: In the phase of the global long wave recession, the national innovation system formed in Russia turned out to be an organizational and institutional innovation timely arranged. Nevertheless, institutional barriers have remained for the TDC. The program of implementing the scientific and technological priorities in Russia is rather scarcely effective because of institutional factors.

Under the current conditions of the global long wave depression, which began in 2020 and, according to our estimates, is to last until 2025, it seems essential to provide a set of such institutional arrangements as organizational, motivational, and coordinating ones that would contribute to the development of public-private partnership instruments and the triple helix. In modern condition it includes such instruments of TDC as development of competence-centers, Foresight, promotion for Startups and so on.
\end{abstract}

Keywords: globalization; long waves; technological development commercialization; innovation; Triple Helix

JEL Classification: $B 52 ; D 02 ; E 32 ; O 32$

*Corresponding author: s.pumyantseva@spbu.ru, e.korostyshevskaya@spbu.ru, g.alpatov@spbu.ru 


\section{Introduction}

The evolution of the economy of any country and the whole world is based on a number of common factors not recognized by the current predominant neoclassical direction of economic thought, but clearly revealing themselves in the history of economic performance, which can be identified based on the analysis of statistical data. The time is not far off when, in the course of the next crisis, the evolutionary-cyclic nature of economic development, in contrast to the concept of linear progress, will lead to the recognition and dominance of a new scientific paradigm, in accordance with the logic of T. Kuhn's scientific revolutions. The interest in them is fostered during a downturn in the development of science, economics and society, when old ideas collapse and there is a strong need to develop new concepts of the meaning and limits of a particular theory implementation.

Innovative development is characterized by the complex of economic, technological, resource, institutional and other forces. These forces are manifested in the cyclical economy movement giving rise to forming stimulus and barriers to innovative development. It is needed is to identify these forces to adapt economic policy thereto. An extensive set of institutions aimed at solving the problems of innovative development is created in Russia. But technological development commercialization (TDC) is progressing slowly yet. There is a need to identify the reasons for this.

Intangible assets play a major role in the operation of companies in the post-industrial economy. Intangible assets are understood in this paper in a broad sense and include, among other things, the behavior of the state and business in the implementation of innovations. The evolution of the innovation process at the global and national level will to a greater extent depend on the intangible assets of its agents.

It is necessary to form an active layer of true entrepreneurs in Russia, and to facilitate them in the process of innovations implementation. The state and educational institutions play a meaningful role in this process providing the innovation with the appropriate infrastructure and competencies.

In the context of global economy, when the global competition in the innovation sector between countries, transnational capital and regions with a cluster structure is on the agenda, the formation of a true innovative entrepreneurship is critically important.

\subsection{Research background}

Recent research of long waves is focused on their technological explanation within the framework of J. Schumpeter's approach, according to W. Kingston [1], as a result, even the institutional factors of long waves, as described by Perez [2], remain underestimated. According to her approach, the change of long waves (Kondratieff waves, K-waves) occurs under the influence of institutional changes, in particular, the old institutional paradigm must be overcome, because it interferes with new technology concept.

The long wave research notes the generation of a cluster of new combinations of economic resources in different countries since the 2008 - 2010 crisis, including new process (3D printers, additive manufacturing, fast Internet, Internet of Things) and business models (platform-based or app-based business models) [3, P.87], eco-innovations allocated in a separate group among the innovations defined by the Oslo Manual [4, P.716], the NBIC cluster and similar bio-medical technologies. Dachs et al [5, P.378] pay attention to the fact that nowadays is a favorable time for the introduction of eco-innovations. At the same time, following the Oslo Manual classification, researchers note only the comparative efficiency of process, product, marketing, etc innovations. The process innovations can have negative effects on employment [5, P. 348] and, hence, on the cumulative causation of 
economic growth are pointed out. In the meantime, the modern cluster of new technologies can be defined as a type of basis innovations in the sense they were considered by $\mathrm{G}$. Mensch [6]. This cluster of technologies can be considered established, but has it been commercialized, that is, transformed into operating businesses forming new industries driving the economic growth? The answer to this question is possible without calculating the correlation between the rates of economic growth and the dynamics of new industries. The assessment of the latter is still difficult due to the small statistics on new industries. To answer the question one should take into account the work of Mensch, rarely recalled in the mainstream of economic science, who showed the absence of an echo effect between inventions and innovations, and the key (triggering) role of long wave depressoin in launching the mechanism of implementation and further diffusion of basis innovations.

It should be noted that the term "basis innovations" is not used in the economic literature, the leading economic journals, except for the assumption that a modern cluster of technologies can provoke a change in the very essence of the business model [3, P.87]. Now we can observe the transition from the hypothesis of an innovation pause [7] reflected the situation of low innovation activity in the 2008-2009 crisis preceding period, confirmed, inter alia, based on the EC data [4, P. 699-703; 8, P. 331; etc], to the stage of technology maturity. At that, the period following the 2008-2010 crisis is treated either as a long-wave rise [4], or as a continuation of the crisis or recession [8, P. 338; 9]. The term "depression" is not used. However, it is emphasized that countries with service based economies were hit by the 2008-2010 crisis more seriously than industrial ones [5].

The technological capacity commercialization, represented nowadays by a set of basis innovations according to Mensch, will be possible in the course of overcoming the depression, therefore it is necessary to identify the connection between the emerging model of innovative entrepreneurship and the triggering nature of depression in this process. According to Block et al, [3, P.85], "future research in entrepreneurship and innovations need to incorporate design that allow for the measurement of causal effects". This means consideration of a larger number of long wave factors than is assumed by the typical Kwaves model in modern literature, based solely on the technology factor. This approach, based on literature and statistics, which there is no sense to discuss hereto, is presented in Rumyantseva, 2003, 2019 [10,11]. Within this approach, one of the leading indicators of the K-waves dynamics is price performance, and the general indicator reflecting the dynamics of financial and credit, innovation and technological, natural resource and information and price factors of long waves can be found in the GDP dynamics. When, in accordance with [6], a long wave depression comes, TDC occurs.

In terms of instruments, TDC [3] was presented by such innovations, different forms of crowdfunding, government VC, startup accelerators, university funds, IP-based financial instruments complementing traditional ways of financing through business angel institutions, VC or bank financing. They view the entrepreneurship education as a way to motivate all actors in this process to take the risk of a startup. In [12], the role of regional clusters, technology parks, holdings, management companies, professional communities, marketing cooperatives, etc., is shown in the process of industries and their companies development. In particular, the role of the common institutional space at national level in the context of globalization is identified. The eco-system of a university's entrepreneur as a whole is under consideration creating more favorable conditions for cooperation between universities, business incubators, technology transfer centers and various financial support institutions [13]. The innovation environment, where "the public sector should be able to prepare an appropriate innovation environment" can also be considered pursue this matter [14]. The benefits and costs of cooperation between economic agents within the relations of such cooperation were considered in [15]. These authors, in particular, within the concept of behavioral abbitionality, have shown that government support for business through 
technological programs launches incentives for companies to innovate as output $[15, \mathrm{P}$. 434]. At the same time, there is an effect of synergy between efforts to support R\&D and internal motivation of companies to apply more $R \& D$ efforts by launching learning processes [15, P. 429, 443]. The system of nurturing enterprises illustrated by one of the Poland regions through the institutional environment, i.e. UN funds, based on the distribution of these funds by enterprises through a network created between universities and businesses, shows the positive impact of an institutional support system improving the innovativeness of enterprises [16]. The relations between universities, business and government are at the core of the well-known Triple Helix concept [17], which, as we have noticed, is hardly mentioned in top-rated journals. Meanwhile, this concept is very significant if considered in a broader context, taking into account the evidence found [9] on the high role of intangible assets for the flexibility and survival of companies in the early and late crisis stages (2008 - 2009 and $2011-2014$ ). Having placed it in an even wider sense of national economies survival under the globalization, it may be shown how important the role of Triple Helix relations is in the formation of national competitiveness.

At the same time, despite the idea that without appropriate general economic conditions (stages of the economic cycle depression) [6], the innovation cluster will not turn into new industries, the necessity of such an impact of depression in the technological sphere remains disputable. It was shown [19] that within the global economy it is no longer individual companies enter into competition, but mainly states and large companies of transnational capital, and now also regions with a cluster structure do. With regard to the need for individual states to preserve their national economy, not only the technological reserve of universities, academies and companies is required, but also the corresponding institutional environment. In this sense, it is shown [18] that the innovation process in the $\mathrm{V}$ long wave will be carried out in the form of public-private partnership transformed into a Triple helix model. If in I-III long waves the centers of regional growth areas in the depression phase were industrial enterprises, then already from the end of the IV long wave, in the transition to $\mathrm{V}$ one, one can observe the creation of such centers in European countries and North America by universities supporting the formation of cities and region, and their survival as it is under the depression.

\subsection{Our early hypotheses}

The proof of the G. Mensch's concept of depression as a trigger for cluster innovations gave an unexpected result - about $80 \%$ respondents agreed that the depression is the best time to implement basis innovations, but not because of low production costs, according to Mensch, but on policy grounds - as one of the respondents wrote in the comment to his questionnaire - "only "committed" employees will remain; you can remove mountains with low investment". Here, the Schumpeterian concept of the innovator-entrepreneur is rather confirmed [19]. However, from the perspective of today's research, does this mean that with a favorable institutional situation right now, in the period of $2020-2025$, a technological breakthrough is possible?

Based on the social fields theory of N.Fligstein, including collective actors trying to set up a majority system and giving a definite sense to counterparties' actions, the hypothesis on the cultural capital importance and cultural patterns of the society for the innovative development of Russia was also checked [20]. These cultural patterns can also be interpreted as intangible assets of society as a whole, influencing the innovative behavior of individuals in various ways. The approaches to the assessment of cultural factors in marketing practice regarding the increasing innovativeness of the cultural sphere have been considered as well [21]. This analysis allows seeing the prospects for the inclusion of 
intangible assets in the formation of economic agents competitiveness strategy in the global post-industrial economy.

The hypothesis that the implementation of the Triple helix concept [17] by large innovative companies in Russia promotes the introduction of organizational innovation was tested. The hypothesis was confirmed. The condition for the implementation of the Triple Helix concept for all companies: entering into various forms of interaction with the state and universities. These forms can be regarded as organizational innovation [19]. It is important that these new relations between the state, business and universities emerged in Russia mainly in the period of $2008-2018$, that is during the recession. This gives faith to the fact that during the current 2020 - 25 depression the availability of appropriate organizational structures will facilitate the implementation of a basis innovations set. Meanwhile, taking into account the above-mentioned discrepancies of experts in determining the current phase of the long wave, the very hypothesis of recession in 2008 2017 (18) and depression in 2020 - 25 requires verification, which is done in clause 3.1 . of this study.

\subsection{Purpose of the article}

This paper is devoted to researching the effect that a phase of the long wave has on technological development commercialization (TDC) in Russia taking into account the trend which has been found for tuning a public-private partnership institution into the Triple Helix mechanism.

\section{Methods}

The studies on the relationship between the economic cycle (or the general economic environment in time) and innovations [22, 4, 9] are limited by the statistical base of $2014-$ 2015, regardless the reference point. Based on the objectives of the study, we have found that the period after 2017 is the most crucial, at least in the US and Russian economies, when trends of long-wave depression began to form. The Bloomberg database contains data for these countries until the 2nd quarter of 2020. Quarterly data has been converted to annual data. The United States has been selected as a key comparison target because of its continuing historic leadership in economic growth and innovations.

\section{Results}

\subsection{Diagnostics of the current long wave stage}

The failure point of economic performance at the stage of prosperity (Fig. 1, Fig. 2) is the 2008 economic crisis marking the upper turning point of the $\mathrm{V}$ long wave. This is the beginning of a steady downtrend towards the lower turning point of a long cycle, the depression. This downward move is mediated by the tension between obsolescent institutions and emerging new technology trends and new institutions. Fig. 2., reflecting the US GDP growth index, also shows a lower level of this indicator in $2011-2015$ in comparison with the previous period of 1990 - 2006, the latter can be characterized as a phase of recovery (before the 2001 crisis) and prosperity (in 2002 - 2006) of the V long wave. Fig. 1 shows the shape of a long wave in the Russian GDP growth index from 2001 to 2020 (RUDPRYOY indicator), it is noticeable that the GDP growth index begins to show downward trends even before the COVID-19 pandemic, in 2018. Fig. 2 demonstrates 
the shape of a long wave in the US GDP growth index (GDP CYOY indicator) from 2000 to 2020 , it is noticeable that negative changes in GDP manifested themselves in a decrease in the overall level of the graph back in 2011 - 2019, that is, before the COVID-19 pandemic, and they are below the values of 2004 - 2006, the phase of long-wave prosperity.

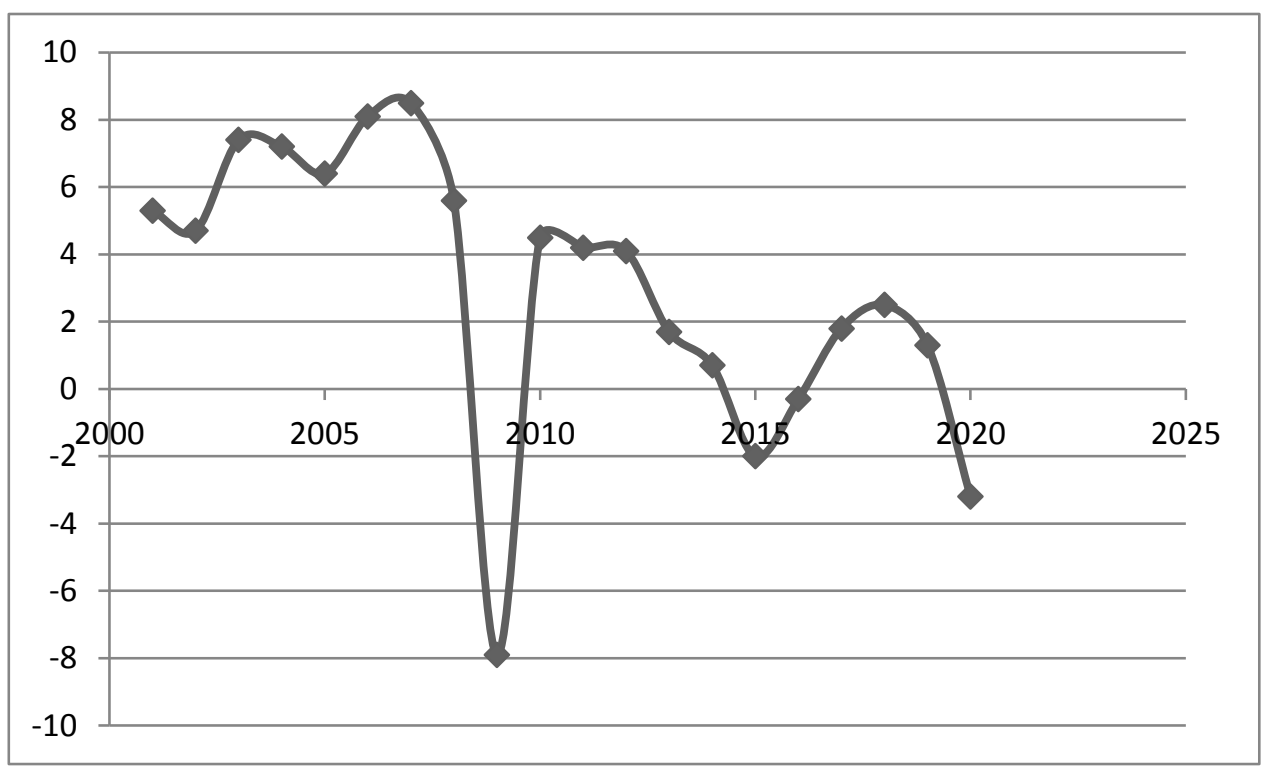

Fig. 1. GDP growth index of Russia (2001 - 2020), RUDPRYOY indicator Calculated as per: www.bloomberg.com (reference date: 02.09.20)

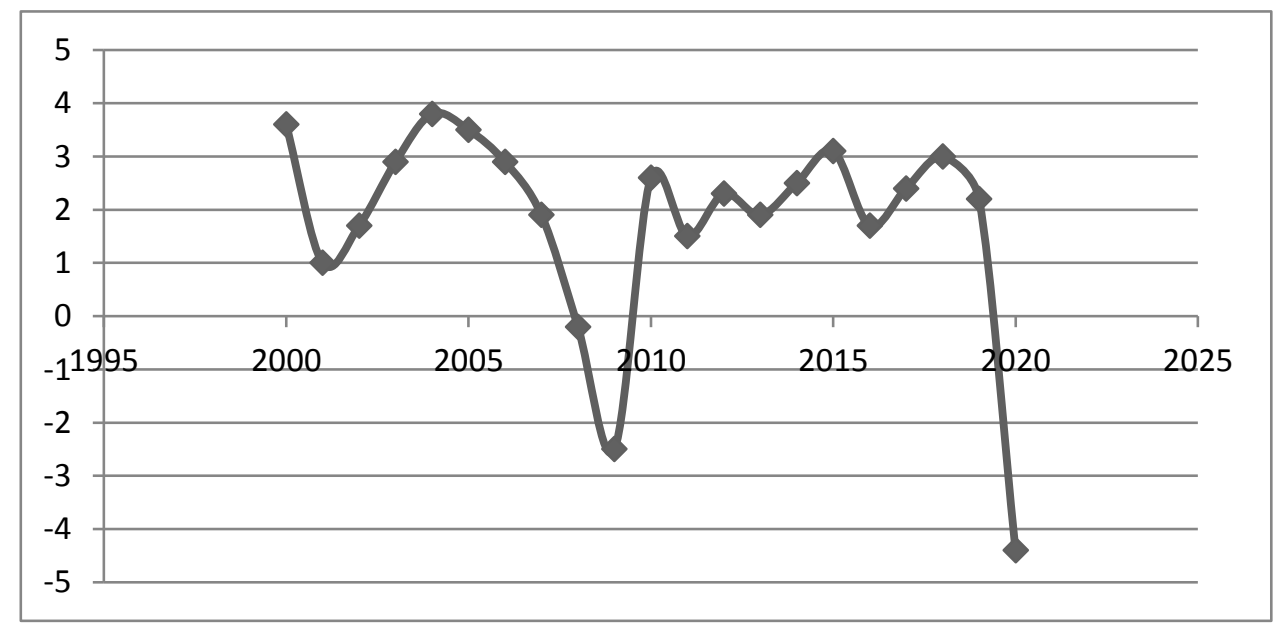

Fig. 2. US GDP growth index (2000 - 2020), GDP CYOY indicator Calculated as per: www.bloomberg.com (reference date: 02.09.20)

The assessment of price performance was also carried out. It has shown deflationary trends both in the United States (starting from November 2018, the producer price index (PPI) began to periodically turn to negative values, from -0.1 that month, to -0.5 in 
February 2020 - the FDIDFDMO indicator), and in Russia (starting from September 2019, at the rate of about $-5 \%$, and down to $-14.1 \%$ in May 2020, with a slight increase to $-2.2 \%$ in July 2020 - the RUPPNEWY indicator). There are no diagrams here, but deflationary dynamics prior to COVID-19 are indicative of recession trends starting in 2018. The pandemic has increased these trends, and the world economy has already entered a real depression phase.

\subsection{Technological capacity and commercialization of technological developments}

The technological and organizational inventions, discoveries and their initial experimental testing in the conditions of narrow market for prestigious or purely scientific consumption, as well as consumption within the framework of a progressive defense-industrial complex are defined as a technological capacity. The technological capacity can be quite extensional and diversified. But, in any case, it represents only a potential that might develop into a broad innovation process with enhancing innovations and general-purpose technologies, or might not.

The movement of the technological and economic paradigm, its institutional structures are considered as a driving and at the same time inhibiting factor of innovative development, according to Perez [2] approach.

Under the circumstances, the transformation of technological capacity into the radical innovations giving rise to new markets and industries, that is according to our definition, TDC is a big task for business and governments.

It is our belief that the propensity for innovations is closely related to the institutional environment in which the innovation process takes place. Under the depression conditions defined above, it is exactly the availability of institutional factors stimulating radical innovations determine the TDC capabilities.

\subsection{Institutional environment of TDC in Russia}

\subsubsection{Basic elements of the TDC institutional environment in Russia}

The Institutes for development are of great importance in stimulating TDC in Russia. Among them: The Russian Foundation for Technological Development, The Foundation for Assistance to Small Innovative Enterprises in Science and Technology, The Russian Bank for Support of Small and Medium-Sized Entrepreneurship, The Bank for Development and Foreign Economic Affairs (Vnesheconombank), The Russian Venture Company (RVC), The Fund for Infrastructure and Educational Programs of Rusnano; The Skolkovo Foundation for Development of Innovation and Commercialization Center; RVC Seed Fund; RVC Infrastructure Fund; RVC International Funds - Russian Venture Capital ILP.

The Institutes for development have powerful resources: and currently the most widespread and demanded are the structures interacting with small and medium-sized businesses, initiated by the federal government in order to subsidize this economy sector, which were created in almost every constituent entity of the Federation. But at the same time, it has been established that the importance of quantitative criteria in assessing the effectiveness of the development institutions activities is overstated. In fact, there are no government measures to improve the efficiency of development institutions.

Support for innovative development is of particular importance for small and mediumsized enterprises (SME). As part of the program of the Ministry for Economic Development of the Russian Federation, a network of SME support infrastructure is being created in the 
regions, including: lending assistance funds (guarantee funds, joint surety funds); microcredit organizations; business support centers; social innovation centers; cluster development centers; regional engineering centers; prototyping centers; certification, standardization and testing centers; national artistic trades centers; export support centers; multifunctional centers for business; commercial, industrial, agro-industrial parks; technology parks; private industrial parks; business incubators. Such support specificates the structure of the national innovation system (NIS) in Russia and makes innovation development more accessible to small businesses.

The State support is associated with the implementation of an active component of innovation policy - programming: the "Smart y", "Start", "Development", "Commercialization", "Internationalization" programs of the Innovation Promotion Fund; Multilateral Cooperation Programs (ERANET); EU Framework Programs; Joint RussianFrench program "Innovative enterprises - Russia"; the RVC's Globalization of the Russian Innovation Industry Program.

In addition, the Strategy for Innovative Development of Russia for the period until 2035 pays great attention to the infrastructure and environment of innovative entrepreneurship, including the development of academic science, which implies the formation of the foundations for the expansion of the triple helix organizational and managerial technologies in Russia.

A restriction for the implementation of this task is the systemic problems of Russian society, such as weak motivation for innovation, administrative and bureaucratic barriers, inconsistency in macroeconomic and innovation policies, opportunistic behavior of a number of innovation market players, tensions between society and the elite, poor awareness of SMEs on the available opportunities, etc.

While the most intensive innovation process is in the field of interaction between science, education and business - that is at universities, where such instruments as business incubators, development commercialization offices, marketing and technology transfer centers, innovative campuses, small innovative companies and startups are engaged.

At that, the entrepreneurship itself notes that the relationship between large innovative businesses and universities is of key importance for TDC. According to the heads of large innovation-oriented companies, the main forms of their interaction with universities include joint projects with universities, the opening of basic departments and training of qualified staff [19].

The academic and technological forecasting, namely the "forecasting - planning programming" complex; science and technology Foresight [23]; technology entrepreneurship training programs for students and teachers, competence centers [12] are acquiring the most important significance.

The latter are actively developing in the modern TDC practice in Russia, being realized through integration into global innovation processes, including integration into global value chains. This allows participants to gain new competencies. Technological competencies are becoming not only a key factor in competitiveness, diversification of activities and sustainable development of countries, regions, businesses and organizations, but also one of the new TDC instruments.

They are a cross-cutting instruments for fostering TDC, and it is the competence-based approach to the organization of high-tech innovation processes that plays a primary role, contributing to the global competitiveness of companies, universities, regions, countries.

In Russian practice, the most dynamic process, at all events associated with the institutionalization of competencies, is implemented at the regional, corporate and university levels (Table 1). 
Table 1. Competence centers in Russia: current situation

\begin{tabular}{|c|c|}
\hline Regional & $\begin{array}{l}\text { Competencies clusters: } \\
\text { 1. Pilot regional innovation cluster (pilot RICs) }-27 \text {; } \\
\text { 2. Industrial clusters }-22 \text {; } \\
\text { 3. Innovative leading clusters }-11 \text {. }\end{array}$ \\
\hline University & $\begin{array}{l}\text { 1. Saint Petersburg National Research University of Information } \\
\text { Technology, Mechanics and Optics: } 5 \text { centers of excellence based on } \\
\text { international laboratories (Photonics and Natural Sciences, "Smart } \\
\text { Materials", Science, Health and Survival, Intelligent Technologies and } \\
\text { Robotics, Information Technologies in the Economy, Social Services, } \\
\text { Arts), etc. } \\
\text { 2. STI University 20.35: competencies in cross-cutting technologies } \\
\text { (artificial intelligence and big data analysis, the use of distributed ledgers, } \\
\text { the Internet of things and cyber systems, virtual and augmented reality, } \\
\text { neural interfaces). }\end{array}$ \\
\hline Corporate & $\begin{array}{l}\text { Central Committee of the State Corporation "Rostec": } \\
\text { 1. Central Committee and the committee of technological superiority of } \\
\text { MNPK JSC in the thematic areas of "Avionics": "Aircraft electronics"; } \\
\text { "Aircrafts CSU"; "Special equipment control systems"; "Avionics } \\
\text { software systems"; "Avionics innovative technologies"; } \\
\text { 2. Central Committee for control and registration systems of Izmeritel } \\
\text { OJSC - the leader of instrument engineering in the Russian Federation; } \\
\text { 3. Open Innovation Center of the Avtomatika Concern; } \\
\text { 4. } 5 \text { clusters of competencies in the basic business areas of Roselectronics } \\
\text { JSC, etc. }\end{array}$ \\
\hline
\end{tabular}

World-class Competence Centers (CC) are equipped with a unique research infrastructure promoting the breakthrough research and the development of basis innovations, and allowing them to make scientific findings, based on which products having no analogues in the world are created, which in turn allows to create new markets and occupy high competitive positions in the global technology space.

The international practices evidence that $\mathrm{CCs}$ contribute to ensuring the global competitiveness of countries, regions, companies, universities, but in Russia this process has not received the expected development yet, in fact, there are no centers of competence of a global nature.

The development of new competencies within the NTI project - NTI University 20.35 includes two stages. The first stage $(2017$ - 2018) relates to the development of a competency model for leaders and teams of STI companies, as well as the formation of a pool of universities and online courses being sources of world-class competencies. The second stage (2019 - 2035) and its final result is the creation of a Platform for multiple competency models for leaders, teams and organizations and a Platform for competency providers - any organizations and individuals, incl. services for packaging competencies in different formats.

NTI CCs do not play alone, but together with a wide range of partners: Russian and foreign universities, commercial companies forming an engineering and learning consortium. Currently each consortium includes 18 organizations. The consortium members participate in co-financing the Center's activities, determine priority areas of research, rules for the distribution of rights to objects of intellectual activity, jointly develop and implement educational programs. The consortium members include Sberbank, Rostec, MTS, Pharmsintez, etc.

The empirical analysis of the history of the world leading companies showed that the competitive advantage of companies was exactly the introduction of organizational and 
institutional innovations during the recessions of the previous long waves, which allowed them to survive the times of depression [10, P. 104-113].

Thus, the analysis of the NIS institutional structure in Russia showed that in the previous period of the recession of 2008 - 2018 there had been the introduction of organizational innovations, which are a preliminary stage for further TDC within the long wave performance, and this process is likely to be continued as part of in-depth research of the competence-based approach to TDC at the second stage of the NTI program development.

\subsubsection{Positive factors of the TDC institutional environment in Russia}

In the institutional and organizational environment of the Russian economy, there is a reserve and the potential for further innovations that would support the actual technological activities of business in the future. In this regard, in order to realize the potential of the "triple helix" mechanism, research and educational organizations should institutionally help by supporting startups in interaction with existing successful businesses.

It is emphasized that the TDC process can be supported not only through direct government participation in the creation of an innovation infrastructure; financing innovative projects, including venture ones; development and implementation of innovation policy, but also through the use of new promising tools. These include tools that are at all events related to scientific and technological forecasting, namely the "forecasting planning - programming" complex; scientific and technological Foresight [23]; TDC instruments in the scope of the Triple Helix model - educational programs for teaching technological entrepreneurship for students and teachers, centers of competence and excellence, regional cluster policy, etc.

\subsubsection{Institutional barriers of TDC in Russia}

- Lack of "easy money" conditioned by the high interest rates on loans, although measures are already being taken to reduce them, in particular for SME

- The imbalance of the innovation space in Russia caused by the concentration of development institutions in the leading regions

- A high degree of bureaucratization in the economy, in particular, elements of opportunistic behavior of officials, difficulties with certification and licensing.

- Low level of transparency of individual development institutions not allowing assessing the effectiveness of their activities

- The predominance of quantitative methods in assessing the development institutions performance

- Lack of a systemic nature of the policy of the constituent entities of the Russian Federation in the field of support and development of innovative businesses export activities

- Lack of qualified staff

- Disregard for organizational innovation at the company level in the preceding recession period

- Lack of information from business entities on the possibilities of cooperation within the National Innovation System with universities and government agencies. 


\section{Discussions}

"In fact" - according to Mensch - "whenever technological stalemates have occurred in the past they have not been caused by a lack of new and useful theoretical knowledge but to the economy's apparent inability to translate this knowledge into practical terms" [6, P. 150]. He called a similar situation "paradox of unused technologies" and noted that it was observed before 1825, before 1873, before 1929 and "can also be observed today", that is, in $1975-79$, just before the upper turning point of the fourth long wave.

The holdback in technological development fits well into the periodization of $G$. Mensch's technological stalemates. Comparing with the periodization of long waves, it is safe to say that a technological stalemate or an innovation pause - that is, a situation when new technologies find serious barriers to widespread adoption in the economy, arise during the upper turning point of a long cycle, at the height of prosperity. Therefore, various qualitative assessments of the composition of the VI long wave's basis innovations cluster even giving the prospect of future growth and the industries content to be based on, does not yet mean that this growth has already begun.

Technological trends taking shape today have not yet overcome the effect of technological stalemate and innovation pause. And the point here is not so much that the indicated paths have not yet matured technologically, but that, according to G. Mensch, not scientists or researchers, are "blamed" of the technological stalemate, but the general economic environment, "inertia in capital reallocation" [6, P.150].

In the downward stages of K-waves, in the phase of the long-wave recession, institutional conditions favor the implementation of mainly process improving and organizational innovations. Those companies that got their bearings in time and went to the organizational re-equipment of their business processes and technological chains in the history of the economy during the recessions, later received a significant competitive advantage during the depression and early revival of the long wave. It subsequently lowered their costs and paved the way for the introduction of basic technological innovations with the subsequent commercialization of the result, even they were old big companies.

At the same time, the institutions creating an environment for innovation compete with each other in time, replace each other in a competitive way and at certain stages act as an obstacle to innovative development. On the other hand, the institutions are largely manmade and their management allows creating an environment for innovations of the required type in accordance with the long wave stage.

In this regard, the motivational factors being on the side of society and the individual and depending on existing social and political institutions, social norms and rules; based on habits, traditions, religions, ideologies, etc., have to be treated and studies as a condition of greater or less innovativeness of a given society. Thus, innovations in the creative industry are being studied today. It is emphasized that to remain competitive in a rapidly changing globalized environment, it must create the right conditions for creativity, together with innovations, to become an integral part of a new business culture [24; 25]. The choice by the young generation of their place in life as an active participant in the socio-economic process depends on these institutional conditions.

Institutions, thus, determine the factors of the formation of entrepreneurial activity and its motivation. In this regard, the motivational factors of innovative entrepreneurial activity, as well as the reduction of the above-mentioned information barriers for business as a coordination mechanism, are critically important.

These motivational factors, through the mechanisms of obtaining a synergistic effect from the cooperation of the subjects participating in the Triple Helix, as already mentioned in section 1.1., are set by the current country economy National Innovation System and its 
structure. Within the globalization, homogenization of markets, consumer practices and the dominance of new network products, it is already difficult to talk about a separate Russian, Polish, Swiss, American and even EU economy in the near future. Despite the regionalization processes caused by the 2008 - 2010 crisis, the unification of trends in economic and innovative development may definitely occur. This will require further elaboration of institutional conditions for the implementation of innovation policy for national companies that will become participants in global competition.

For future research, we believe it is necessary to develop an approach focused on centers of excellence as an element of the national innovation system and TDC instrument. In this regard, it is necessary to develop a new approach to organizing a system of competence centers based on universities as key participants in the innovation space, with an emphasis on new principles for organizing such centers, ensuring the growth of creative potential and balancing the interests of all participants in the innovation process at the state and specific regions level.

It is also necessary to develop proposals for improving the mechanism of competence centers functioning on the basis of the university, taking into account a new approach to their organization, including the development of a system for assessing such centers performance quality and a list of recommendations for adjusting educational standards of higher education, with regard to the need to form a target level of creative potential in the regional and national scale.

It is required to pay attention to the institutions necessary to support small innovative businesses. This raises questions of the following order. 1) What is the optimal number of development institutions required for the successful functioning of innovative SMEs? 2) What kind of development institutions does SME need, and in what combination are they required for the emergence and successful functioning in this region? 3) What is the principle of building development institutions contributing to the significant development of small innovative business: territorial, sectoral, functional, other? What functions should development institutions perform for the successful functioning of small enterprises? A number of other questions can be attributed to the topical general ones, including how to determine the effectiveness of funds spent on the creation of development institutions? Who should bear the costs of creating and functioning of the development institutions and maintaining their effective work: the state, regions, business, and other structures?

\section{Conclusion}

In our opinion, to implement the potential of organizational innovations introduced in the $\mathrm{V}$ long wave of recession in Russia, the active development of training programs for technology entrepreneurs is required. An important task is to familiarize the heads of innovation-oriented companies with TDC instruments, including new ones, such as foresight and competence centers, alternative exchange platforms, technology transfer centers at universities and others noted by us and other researchers (clause 1.1.).

Under the current conditions of the long-wave depression began in 2020 and lasting, according to our estimates, until 2025, there is a need for a set of institutional measures, including organizational, motivational, coordination and legislative changes that would contribute to the development of public-private partnership and the triple helix instruments. Under present-day conditions, they include such TDC instruments as the development of competence centers, scientific and technological foresight, work with startups of small innovative companies, as well as coordination, information and innovation centers.

As we succeeded to show, based on the analysis of public-private partnership practice and the history of long waves, during the downward stages of long waves, an organizational and institutional environment is usually created to support the innovation process in the 
course of interaction between the state and business [18]. In this sense, we believe that the innovation process in the VI long wave will be carried out in the form of public-private partnership transformed into a triple helix model. The implementation of the "triple helix" concept by large innovative companies in Russia promotes the introduction of organizational innovations. And in many respects, during the $\mathrm{V}$ long wave recession in $2010-2018$, such an environment was created and it was done in time.

For the future development of the country and its business, it is necessary to focus on the use of this environment and the inclusion of its components in the sphere of their competence as intangible assets by economic agents. The significance of the latter will only grow in the economy of the long-wave depression of 2020 - 25 and after overcoming it.

The world economies face difficult times, when depression trends laden with the COVID-19 pandemic could push national economic development far back. But, possibly, such a combination of conditions will push the development of new sectors within the cluster of basis innovations emerged during the upper turning point of the $\mathrm{V}$ long wave (2008 -2010 crisis). And they, as can already be expected, will indeed be based on biomedical and additive technologies.

\section{References}

1. Kingston, W. (2006). Schumpeter, business cycles and co-evolution. Industry and Innovation, 13(1), 97-106.

2. Perez, K.. (1983). Structural changes and assimilation of new technologies in the economic and social system. Futures, 15, 357-375.

3. Block, J., Fisch, C., van Praag, M. (2017). The Schumpeterian entrepreneur: a review of the empirical evidence on the antecedents, behavior and consequences of innovative entrepreneurship. Industry and Innovation, 24(1), 61-95.

4. Jakimowicz, A., Rzeczkowski, D. (2019). Firm ownership and size versus innovation activities over the business cycle: near-zero inertia as a sign of the transition from the fifth to the sixth Kondratieff wave. Oeconomia Copernicana, 10 (4), 689-741.

5. Dachs, B., Hud, M., Koehler, C. Peters B. (2017). Innovation, creative destruction and structural change: firm-level evidence from European countries. Industry and Innovation, 24(4), 346-381.

6. Mensch, G. (1979). Stalemate in technology. innovation overcome the depression. Cambridge, Massachusetts: Ballinger Publisching Company.

7. Polterovich, V. (2009). The Innovation Pause Hypothesis and the Strategy of Modernization. Voprosy Ekonomiki, 6, 4-23. (In Russ.)

8. Spescha, A., Woerter, M. (2019). Innovation and firm growth over the business cycle. Industry and Innovation, 26(3), 321-347.

9. Landini, F., Arrighetti, A., Lasagni, A. (2020). Economic crisis and firm exit: do intangibles matter? Industry and Innovation, 27(5), 445-479.

10. Rumyantseva, S. (2003). Long waves in the economy: multifactor analyses. St.Petersburg: State University Publishing House. (In Russ.)

11. Rumyantseva, S. (2019). The economic matter movement and the mechanism of business cycle. TEM Jornal - Technology, Education, Management, Informatics, 8(2), 507-515.

12. Korostyshevskaya, E., Chudakov, A. (2020). Promises for cluster progression: Russian automotive market outlook. In: Kliestik, T. (Eds.), Globalization and its Socio- 
Economic Consequences 2019 (Article Number 06012). Rajecke Teplice: SHS Web of Conference.

13. Kobylińska U., Lavios, J. (2020). Development of research on the university entrepreneurship ecosystem: trends and areas of interest of researchers based on a systematic review of literature. Oeconomia Copernicana, 11(1), 117-133.

14. Juris, R., Cugova, A. (2020). Innovative environment in the country and its importance in terms of business innovation as a precondition for the financial performance of company. In: Kliestik, T. (Eds.), Globalization and its Socio-Economic Consequences 2019 (Article Number 02008). Rajecke Teplice: SHS Web of Conference.

15. Cerulli, G., Gabriele, R. Potì, B. (2016). The role of firm R\&D effort and collaboration as mediating drivers of innovation policy effectiveness. Industry and Innovation, 23(5), 426-447.

16. Lewandowska, A., Stopa, M. (2018). SMEs innovativeness and institutional support system: the local experiences in qualitativeve perspective. Polish case study. Oeconomia Copernicana, 9(2), 333-351.

17. Etzkowitz, H. (2008). The triple helix: university-industry-government innovation in action. UK: Routledge.

18. Rumyantseva, S., Korostyshevskaya, E. (2019). State-private partnership in the history of innovation long waves. In R.M. Nizhegorodtsev, N.P. Goridko (Eds.). Control for Innovations. Proceedings of the international scientific and practical 2019 conference. (pp. 33-40). Novocherkassk: South Russian Polytechnical State University (NPI).. (In Russ.).

19. Korostyshevskaya, E., ,Samylov, I., Rumyantseva, S. (2018). Incentives and barriers for commercialization of technological developments in Russia (empirical study). Innovation, 10, 55-62. (In Russ.)

20. Rumyantseva, S., Musaeva, A. (2018). Neil Fligstein's concept of organizational fields, economic processes and dynamics, and their significance for building Russian markets. In J. K. Hass (ed.), Re-Examining the History of the Russian Economy (pp. 243-276), Palgrave Macmillan.

21. Koltsova, A., Alpatov, G., Volkova, A. (2020). Culture in the global economy: features of cultural goods on the threshold of a knowledge economy and increasing the country's competitiveness. In: Kliestik, T. (Eds.), Globalization and its SocioEconomic Consequences 2019 (Article Number 01015). Rajecke Teplice: SHS Web of Conference.

22. Spescha, A., Woerter, M. (2019). Innovation and firm growth over the business cycle. Industry and Innovation, 26(3), 321-347.

23. Korostyshevskaya, E., Rumyantseva, S., Samylov, I. (2017). Determination and realization of scientific and technological priorities of Russia in the context of globalization. In T. Kliestik (Ed.), Globalization and its socio-economic consequences, 17th international scientific conference. University of Zilina, Proceedings (Part III (pp. 1044-1051). Rajecke Teplice: Conference Proceedings.

24. Majduchova, H., Bartekova, M. (2019). Innovations in the creative industry entities. In: Kliestik, T. (Eds.), Globalization and its Socio-Economic Consequences 2019 (Article Number 02009). Rajecke Teplice: SHS Web of Conference.

25. Sagatova, S. (2020). The impact of globalization on the development of creative industries businesses. In: Kliestik, T. (Eds.), Globalization and its Socio-Economic Consequences 2019 (Article Number 04023). Rajecke Teplice: SHS Web of Conference. 